\title{
Analysis of Rainfall Probabilities for Strategic Crop Planning in Raipur District of Chhattisgarh State
}

\author{
SANJAY BHELAWE, N. MANIKANDAN, RAJESH KHAVSE, \\ J.L. CHAUDHARY and S.R. PATEL
}

Department of Agrometeorology, Indira Gandhi Krishi Vishwa Vidyalaya, Krishak Nagar, Raipur (Chhattisgarh)- 492 006, India.

http://dx.doi.org/10.12944/CWE.10.1.30

(Received: December 27, 2014; Accepted: April 15, 2015)

\begin{abstract}
Rainfall data of recent forty three years (1971-2013) of Labhandi station, Indira Gandhi Krishi Vishwavidhyalaya Raipur, Chhattisgarh was analysed with the method of incomplete gamma probability. The data revealed that the average rainfall of labhandi station is $1202 \mathrm{~mm}$ spread over 61 rainy days. Out of this 1055, 68, 53 and $27 \mathrm{~mm}$ received from south west monsoon (JuneSeptember), north east (October-December), summer (March-May) and winter season (January -February) respectively. Probability for receiving more than $100 \mathrm{~mm}$ of rainfall can be expected only at $25 \%$ probability level and that too in four weeks which is leading to the interpretation that rainfed rice production is a challenging task in this region. It has been found that at 75 per cent assured probability level rainfall of more than $200 \mathrm{mms}$ can be expected only in July and August months and this rainfall is hardly sufficient for meeting the water requirement in upland situations. However at 50 per cent probability which is equivalent to average condition, cultivation of rice is possible under well water management conditions. On seasonal basis rainfall at assured probability level of $75 \%$ is not sufficient as the quantity is $795 \mathrm{~mm}$ rainfall in south-western monsoon season.
\end{abstract}

Key words: Crop planning, Rainfall probability, Chhattisgarh.

\section{INTRODUCTION}

Rainfall is the single most important factor in crop production programme particularly under dry lands areas. Of all the climatic factors, rainfall is of greatest concern to population in rainfed agriculture. The variation of monsoonal and annual rainfall in space and time are well known and this inter-annual variability of monsoonal rainfall has considerable impact on agricultural production, water management and energy generation Analysis of annual, seasonal and monthly rainfall of a region is useful to design water harvesting structure. Similarly weekly rainfall analysis give more useful information in crop planning (Sharma et al.,1979). Earlier workers have worked out the weekly rainfall probabilities for different agro climatic regions (Ray et al.1980 and Agnihotri et al.,1986). Gupta et al.(1975) suggested that the rainfall at 80 per cent probability can safely be taken as assured rainfall, while that of 50 per cent probability is the medium limit for taking dry risk. According to Mulat et al., 2004, the quantum of rainfall during crop growing season and temporal distribution of rainfall is a crucial factor deciding interannual fluctuations in national crop production security. On the similar lines, Von Braun (1991) also commented that a $10 \%$ decrease in monsoonal rainfall from the long-period average generally translates into a $4.4 \%$ decrease in the national food production. Rainfall in much of the country is, on the other hand, often erratic and unreliable and can be considered as gamble; and resultant droughts 
due to negative departure of rainfall have historically been major causes of food shortages and famines (Wood, 1977; Pankhurst and Johnson, 1988).

There have been different techniques for determining probability distribution on rainfall analysis and best fit probability distribution function such as normal, log-normal, gumbel, weibull and Pearson type distribution have been identified as per different research studies. Fisher (1924) studied the influence of rainfall on the yield of wheat in Rothamasted and concluded that distribution of rainfall during a season is determining factor rather than total amount of rainfall which influences the crop yield. Another useful line of work relating to the study of rainfall distribution was introduced by Manning (1950) and a transformation of the skew frequency distribution of rainfall was performed to close down to the theoretical normal distribution.

Bhargava et al. (1971) also showed that for a number of crops under Indian situation the distribution of rainfall over the season has a great influence on the yield. Ramana Rao et al. (1975) analyzed the daily rainfall data of Bijapur for the period 1921 - 1970. Biswas and Khambete (1989) computed the lowest amount of rainfall at different probability levels by fitting gamma distribution probability model on weekly basis of 82 stations in dry farming tract of Maharashtra. Upadhaya and Singh (1998) stated that it is possible to predict rainfall fairly accurately using various probability distributions for certain returns periods although the rainfall has inconsistent nature both spatially and temporarily.

In Chhattisgarh state, there are large variations in annual rainfall and these variations often result in reduced crop productivity especially rice crop. Rice is grown in approximately 3.6 million hectares area and farmers take tall and photosensitive varieties for some reasons which flower by mid-October and mature by mid-November. Terminal drought is a recurring feature for rice crop in this region. Also intermittent dry spells make the crop operations dealyed as 80 per cent of the area in this region is under rainfed conditions. Thus, the success of rice crop depends upon not only the monsoonal rainfall but also on the October rainfall which occurs due to cyclonic activity in the Bay of

Table 1: Monthly and seasonal expected rainfall amount ( $\mathrm{mm})$ at different probability levels at Labhandi station, Raipur

\begin{tabular}{lcccc}
\hline \multirow{2}{*}{ Months } & \multicolumn{4}{c}{ Probability levels } \\
\cline { 2 - 5 } & $\mathbf{9 0} \%$ & $\mathbf{7 5 \%}$ & $\mathbf{5 0 \%}$ & $\mathbf{2 5 \%}$ \\
\hline January & 0 & 0 & 6 & 26 \\
February & 0 & 1 & 11 & 23 \\
March & 0 & 0 & 10 & 19 \\
April & 0 & 3 & 12 & 20 \\
May & 2 & 9 & 16 & 36 \\
June & 76 & 101 & 144 & 221 \\
July & 136 & 214 & 321 & 451 \\
August & 160 & 228 & 349 & 457 \\
September & 62 & 100 & 192 & 232 \\
October & 1 & 14 & 34 & 68 \\
November & 0 & 0 & 0 & 16 \\
December & 0 & 0 & 0 & 4 \\
Season & & & & \\
Winter (Jan-Feb) & 0 & 8 & 19 & 40 \\
Summer (Mar-May) & 16 & 25 & 40 & 70 \\
Southwest monsoon (Jun-Sep) & 702 & 795 & 1040 & 1207 \\
Northeast monsoon (Oct-Dec) & 8 & 23 & 52 & 120 \\
\hline
\end{tabular}


Bengal. As the Chhatisgarh plains in central India are mainly dependant on monsoon rains (south-west), the precise knowledge of amount of rainfall that can be expected at different probability levels will go a long way in helping farmers to plan their agricultural operations (Rao et al. 1968). Therefore, an attempt has been made for probability analysis of long term rainfall data of Labandi station for developing risk proof technologies for rainfed agriculture of Raipur district.

\section{MATERIALS AND METHODS}

Daily rainfall data of the recent past 43 years (1971-2013) of Labhandi station, Indira Gandhi Krishi Vishwavidhyalaya Raipur, Chhattisgarh has been scrutinized for correctness of data and converted into weekly, monthly, seasonal and annual format using weathercock software. The weekly rainfall data then analyzed with the help of Weibulls formula as followed by Jadav et al.1999

$$
P=\{(m / n+1) / 100\}
$$

Where, $P$ is plotting position in percentage, $\mathrm{m}$ is the rank of magnitude and $\mathrm{n}$ is number of year for which the data are taken. Rainfall at various probability levels $(25,50,75$ and 90 percent) for weekly, monthly, seasonal and annual basis has been worked out and are presented in Table 1 and 2.

\section{RESULTS AND DISCUSSION}

Analysis of rainfall data showed that on an annual basis, rainfall of the Labhandi station is 1202 $\mathrm{mm}$ received in 61 rainy days. The mean monthly rainfall of labhandi is 189, 337, 337 and $191 \mathrm{~mm}$ in the month of June, July, August and September, respectively with a total monsoon rainfall of 1054 $\mathrm{mm}$ on the data base of 1971-2013.

However when the monthly statistics has been put to probability analysis the rainfall quantity comes down drastically at $90 \% .90$ per cent probability means that we can expect this rainfall quantity in 9 out of 10 years. However, the assured probability level of $75 \%$ which is considered as assured rainfall in 3 out of 4 years. On annual basis, this quantity $1023.2 \mathrm{~mm}$, at 50 probability annual rainfall quantity is $1231.8 \mathrm{~mm}$ and at $25 \%$ probability, annual rainfall quantity is $1397.5 \mathrm{~mm}$. Moreover, August happens to be wettest month with rainfall quantity of $160,228,349,457 \mathrm{~mm}$ at $90 \%, 75 \%, 50 \%$

Table 2: Expected weekly rainfall amount ( $\mathrm{mm})$ at different probability levels

\begin{tabular}{|c|c|c|c|c|}
\hline \multirow[t]{2}{*}{ Standard week } & \multicolumn{4}{|c|}{ Probability levels } \\
\hline & $90 \%$ & $75 \%$ & $50 \%$ & $25 \%$ \\
\hline $23\left(4^{\text {th }}\right.$ to 10 June $)$ & 0 & 0 & 6 & 32 \\
\hline $24\left(11^{\text {th }}\right.$ to $17^{\text {th }}$ June $)$ & 1 & 7 & 28 & 64 \\
\hline 25 (18th to 24 th June) & 5 & 17 & 46 & 80 \\
\hline 26 (25th to 1 st July) & 11 & 19 & 54 & 98 \\
\hline 27 (2nd to 8th July) & 10 & 24 & 53 & 78 \\
\hline 28(9th to 15 th July) & 14 & 43 & 74 & 99 \\
\hline 29 (16th to 22 nd July) & 17 & 38 & 58 & 111 \\
\hline 30 (23rd to 29th July) & 6 & 23 & 60 & 95 \\
\hline 31(30th to 5th August) & 10 & 35 & 62 & 110 \\
\hline 32(6th to12th August) & 16 & 36 & 71 & 104 \\
\hline 33(13th to 19th August) & 9 & 27 & 77 & 126 \\
\hline 34(20th to 26th August) & 6 & 26 & 47 & 84 \\
\hline 35(27th to 2nd September) & 4 & 23 & 56 & 93 \\
\hline 36(3rd to 9th September) & 3 & 22 & 45 & 82 \\
\hline $37(10$ th to 16 th September) & 11 & 19 & 29 & 61 \\
\hline $38(17$ th to $23 r d$ September) & 0 & 1 & 12 & 61 \\
\hline 39(24th to 30th September) & 0 & 3 & 13 & 47 \\
\hline
\end{tabular}


and $25 \%$ probability level and its quantity is more than July month. It leads to conclusion that there is need of more preparedness on part of the farmers to go for water management practices (conservation \& harvesting) in the months of July and August. Moreover, there is water conservation scope in the month of August which can later be utilized for rice crop at reproductive phase in the month of October. Rainfall quantity is falling drastically in the month of October and at 50 per cent probability, the expected rainfall is $34 \mathrm{~mm}$ only.

Similarly seasonal basis analysis has been carried out at different probability levels. At 50 per cent probability, there is expected rainfall of 1040 $\mathrm{mm}$ in south-western monsoon season while at $75 \%$ probability level assured rainfall of $795 \mathrm{~mm}$ which is not sufficient for meeting the water requirement of long duration rice variety and even medium duration rice variety. Therefore, here lies risk in rainfed rice production as well a need for water harvesting in On Farm Reservoirs (OFRs) farm ponds and other harvesting structures as per farming situation basis.

However, it is the distribution of rainfall on weekly basis which is very important and rainfall quantity expected at $75 \%$ probability is less than $50 \mathrm{mms}$ in almost all the weeks during south west monsoon period which adds uncertainty factor in rainfed rice production. Standard week number 28 is receiving highest rainfall quantity of $43 \mathrm{~mm}$ which can satisfy minimum water requirement of percolation and ET losses for rice crop. However at $50 \%$ probability which means on every alternate year basis, there is definite rainfall receipt of more than $45 \mathrm{~mm}$ per week during the period between 25 and 36 standard weeks and this period is in between 18 June and 9 September. Agricultural strategies, farming operations need to be based on this type of analysis and advisories should be planned accordingly.

\section{REFERENCES}

1. Agnihotri Y., Madukar R.M. and Singh P., Weekly rainfall analysis and agricultural droughts at Chandigarh, Vayumandal, 16:5456 (1986).

2. Bhargava P. N., Pradhan, A., Das M. N., Influence of rainfall on crop production, JNKVV Research Journal 8(1): 22-29(1974).

3. Biswas B.C. and Khambeta N.K., Distribution of short period rainfall over dry farming tract of Maharashtra. Journal of Maharashtra Agricultural University,12:157-168 (1974).

4. Fisher R.A., The influence of the rainfall on the yield of wheat at Rothamsted. Philosophical transaction of the Royal Society of London. Series B, 213. (1924).

5. Gupta R. K., Rambabu and Tejwani K.G., Weekly rainfall of India for crop planning programme, Soil Conservation Digest, 3: 31-39 (1975).

6. Jadhav J.D., Mokashi D.D., Shewale M.R. and Patil J.D., Rainfall probability analysis for crop planning in scarcity zone of Maharashtra, Journal of Agrometeorology, 1: 59-64 (1999).
7. Manning H.L., Confidence limits of monthly rainfall, Journal of agricultural science, 40:169 (1950).

8. Mulat D., Guta F. and Ferede T., Agricultural development in Ethiopia: are there alternatives to food aid? Unpublished research report, Addis Ababa (2004) .

9. Pankhurst R. and Johnson D.H., The great drought and famine of 1888-92 in northeast Africa. In The ecology of survival: case studies from northeast African history, Lester Crook Academic Publishing, London (Eds. Johnson, D.H. and Anderson D.M. ), 47-72 (1988).

10. Ramana Rao, B.V., Kavi P.S. and Sridharan P.C., Study of rainy days and wet spells at Bijapur, Annual Arid Zone. 14 (4): 371-372 (1975).

11. Rao Murali, Mohana E.V. and Ramana Rao B.V., The reliability of talafall during cropgrowing season in Mysore Stllte, Ballgalore and Kolar Districts, Mysore Journal of Agric. Sci., 2: 195-205(1968).

12. Ray C.R., Senapati P.C. and Lal R., Rainfall analysis for crop planning, Gopalpur (Orissa). Journal of Agricultural Engineering, 17: 1-8 
(1980).

13. Sharma H.C., Chauhan H.S. and Sewa Ram, Probability analysis of rainfall for crop planning, Journal of Agricultural Engineering, 16:887-34(1979).

14. Upadhaya A., and Singh S.R., Estimation of consecutive day's maximum rainfall by various methods and their comparison, Indian Journal of S. Cons., 26 (2): 193-2001(1998).

15. Von Braun J., A policy agenda for famine prevention in Africa. Food Policy Statement No.13, IFPRI, Washington DC (1991).

16. Wood A., A preliminary chronology of Ethiopian droughts. In: Drought in Africa International African Institute, London, Eds. Dalby D., Church R.J.H., Bezzaz F., 2:68-73 (1977). 